\title{
REMOÇÃO CIRÚRGICA DE ODONTOMA EM ÂNGULO MANDIBULAR: CONSIDERAÇÕES E ABORDAGEM CIRÚRGICA
}

Bruno Tochetto PRIMO, Nelson Luis Barbosa REBELLATO, Diego José STRINGHINI, Leandro Eduardo KLUPPEL, Paulo Roberto MULLER

Os odontomas são classificados como tumores odontogênicos, com crescimento lento e comportamento não-agressivo, geralmente descobertos na segunda década de vida, sem predileção significativa por gênero. Embora predominantemente associados com os dentes permanentes, também ocorrem em associação com os dentes decíduos e são muitas vezes envolvidos com os dentes impactados. Dois pacientes com queixa de aumento de volume em região de ângulo mandibular, com sinais, sintomas e exames de imagem compatíveis com odontoma complexo, associado a dentes impactados na base da mandíbula foram tratados pela técnica da osteotomia sagital do ramo mandibular (OSRM). Esta técnica foi escolhida para minimizar a remoção de tecido ósseo sadio, o que poderia fragilizar a estrutura óssea mandibular. Com o uso da OSRM foi possível realizar a exérese total dos tumores e extração dos dentes sem comprometimento sensorial ou motor permanente. Foi possível observar também 0 restabelecimento da oclusão pré-operatória. As complicações potenciais devem ser analisadas em situações de lesões extensas e dentes profundamente retidos quando a cirurgia por acesso pela cortical vestibular ou lingual requer a remoção extensiva de osso alveolar, sendo que a OSRM pode ser uma técnica alternativa nessas situações.

Palavras-Chave: Odontoma; Tratamento; Tumores Odontogênicos 